\title{
MANUSCRITOS EM SÉPIA, IMAGENS DA MIUDEZA: legados de Walter Benjamin
}

MARX, Ursula; SCHWARZ, Gudrun; SCHWARZ, Michael; WIZISLA, Erdmut (eds.). Archivos de Walter Benjamin. Fotografias, textos y dibujos. Tradução de Joaquín Chamorro Mielke. Madrid, (Círculo de Bellas Artes/Sociedad Estatal de Conmemoraciones Culturales), 2010.

\section{Chrystian Wilson Pereira*}

Tecido em um tempo de crises, o pensamento de Walter Benjamin permanece como um caminho privilegiado de acesso a leituras críticas da modernidade. Até a morte prematura aos 48 anos, Benjamin (1892-1940) ambicionou a perpetuação de seus escritos e registros, levando consigo o desejo de que parte de sua contribuição conseguisse ser salvaguardada. Deixou rastros de sua estadia em um mundo que repensava seus paradigmas interpretativos, mergulhado na catástrofe. Benjamin não se resumiu, contudo, a um espírito inquieto na era dos grandes totalitarismos. Fez-se homem de admirável autoconsciência histórica, inadaptado a uma Europa hostil da qual se retirou em última instância, suicidando-se na fronteira entre França e Espanha.

A relação íntima e zelosa de Benjamin com os próprios arquivos, juntamente com a noção da volatilidade e do perigo que os circundava, originaram um profundo e paradoxal esforço conservacionista. Forçado a calar-se, foi um indivíduo impróprio à ditadura da crença no progresso. Por meio da batalha pela conservação de seus arquivos - e da própria vida -, encontrava um contraposto ao seu silêncio.

\footnotetext{
* Graduando em História pela Universidade do Estado de Santa Catarina. E-mail: chrystianwilsonpereira@gmail.com.
} 
A sensibilidade de Benjamin ao acelerado fluir do tempo permitiu a sobrevivência de grande parte de suas coleções à primeira metade do século XX. A constante luta contra o desaparecimento e a dispersão de seus materiais é uma das motivações de "Archivos de Walter Benjamin: fotografias, textos y dibujos”, publicado inicialmente na Alemanha em 2006 para acompanhar uma mostra da Academia de Artes de Berlim. Também divulgada juntamente com uma exibição de arquivos de Benjamin realizada pelo Círculo de Belas Artes de Madrid, a edição espanhola ${ }^{1}$ foi lançada em 2010 e traduzida por Joaquín Chamorro Mielke. Os autores da publicação, Ursula Marx, Gudrun Schwarz, Michael Schwarz e Erdmut Wizisla, organizaram 13 capítulos, cada um deles precedido por citações do próprio Benjamin e acompanhado de pequenos textos introdutórios ao material apresentado no original alemão. Destaca-se, na edição espanhola, a qualidade de reprodução das imagens e digitalizações dos manuscritos. Grande parte do material não ganhou tradução para o espanhol, salvo algumas legendas de fotografias, notas explicativas e bilhetes, além de listas de frases e palavras proferidas por Stefan, filho de Benjamin, e anotadas por este.

A organização do livro é temática: cada capítulo traz uma parte dos arquivos aqui reunidos do pensador alemão, originalmente espalhados ao redor do mundo nas mãos de familiares, amigos e conhecidos do próprio Benjamin. Foram realizadas classificações subjetivas: cada uma das treze seções tem o título de uma frase do próprio autor pesquisado. Estas compõem pequenas narrativas não somente da vida pública de um intelectual, mas de seus gostos e manias; intenções de escrita; maneiras de guardar e organizar papéis. Não obstante, essas narrativas se formam a partir de rastros das próprias estratégias de sobrevivência, em pleno Terceiro Reich, de um intelectual alemão judeu e de tendências marxistas.

É possível vislumbrar diferentes facetas de Benjamin: o viajante, o pai, o fotógrafo, o desenhista, o ensaísta. Cada seção apresenta um vetor biográfico acerca do autor e, ainda que os textos careçam de maior detalhamento e aprofundamento para um leitor mais interessado (nenhum ultrapassa as quatro páginas), cumprem a função de apresentar os inéditos arquivos ao grande público. Há muitas fotografias: passagens de Paris (SCHWARZ, 2010, p. 218); quadros de lugares pelos quais passou, alguns destes imprimidos em cartões postais (p. 151); e mesmo um retrato de Stefan, seu filho (p. 92). A paixão de Benjamin por viajar; a forma com que observava o vocabulário de Stefan; a incessante busca por inovações estilísticas na

\footnotetext{
${ }^{1}$ Esta resenha é referente à edição em espanhol de 2010.
} 
própria escrita e a fascinação por Paris são alguns inusitados contornos de uma personagem que o livro insiste em desenhar a partir de suas próprias criações.

Os registros manuscritos de Benjamin criam constelações heterogêneas e evidenciam um indivíduo perfeccionista; habituado a dar acabamentos estéticos a seus rascunhos, cartas e anotações. Nos arquivos apresentados no capítulo “De lo pequeño a lo minúsculo”, é possível visualizar um estilo minimalista de escrita, traduzido em uma “economia de expressão" (MARX, 2010, p. 56). Benjamin concebia a estética do pequeno como produto do ato reflexivo e da concentração adultas; do cuidado e da exatidão. Seus manuscritos, salvo raras exceções, anunciam uma escrita fina, precisa e delicada; quase nunca descuidada. Para Ursula Marx, a caligrafia benjaminiana possui, simultaneamente, um ar de mistério e uma aparência de fragilidade, configurando-se como um objeto de percepção sensorial; uma imagem a ser contemplada (2010, p. 57). O estilo lacônico de Benjamin se contrasta, em meio à sua predileção pelo diminuto, às cores cinzentas de sua própria contemporaneidade e, deste modo, revela uma intensa sensibilidade ao ritual que envolve a submersão de ideias no papel.

Benjamin possuía vários cadernos. Muitos destes se perderam com o tempo; no entanto a publicação traz digitalizadas algumas páginas de pequenos blocos remanescentes. Nestes instrumentos foram registrados dados e pensamentos de um intelectual ativo acerca de assuntos diversos, de formas muitas vezes desorganizadas (WIZISLA, 2010, p. 131). Benjamin tinha certo culto por estes blocos, motivo pelo qual lhes prestava atenção especial. Funcionavam como campos de experimentos multifuncionais; uma espécie de material intermediário no processo de suas criações, nos quais reunia pensamentos e frases inspiradoras. Serviam também como diários, suportes de cartas, índices bibliográficos. Alguns apontavam títulos de livros lidos; outros guardavam citações destas leituras, antecipando futuros trabalhos. Concentrava-se, nestes materiais, uma tensão criativa pela qual Benjamin repensava e refazia, de modo constante, o próprio trabalho.

É possível deparar-se, na observação destes “delicados alojiamentos” (WIZISLA, 2010, p. 128), com a face dinâmica de um intelectual. Walter Benjamin: um homem de letras que perfez seu caminho na transdisciplinaridade, mesmo quando isto lhe custava penosas dificuldades no meio acadêmico - afastando-o deste. Daí advém a ampla gama de seus objetos e temas de estudo, evidenciada nestes blocos de nota. Benjamin viveu em uma época na qual as especializações constituíam um pré-requisito para vinculações universitárias. Defendia, no entanto, a liberdade de opinião. Criticava, com isso, a associação do pensamento acadêmico ao Estado e a grupos particulares; rejeitava os fundamentalismos ideológicos. 
Benjamin concebia o conhecimento como uma construção aberta, dinâmica e historicizada. Saboreava, mais do que as particularizações disciplinares, a inquietude do intelectual e o seu permanente questionar. Era filósofo da arte e teórico literário, mas também poeta e historiador. Cabe pensar: não seriam estes blocos de notas, anunciados como vestígios de seu apreço por um trânsito frenético de ideias, um emblema de sua conturbada vida intelectual; uma metáfora da vontade de sobreviver à tempestade da civilização industrial?

Os textos e imagens apresentados no livro, aparentemente menores, podem surpreender o leitor. Tanto por trazerem manuscritos que remetem a notórios e conhecidos trabalhos de Benjamin quanto por revelarem facetas menos conhecidas de sua personalidade. Este é notavelmente um dos grandes méritos da publicação. A seção intitulada "Escritura dispersa” (WIZISLA, 2010, p. 40) reúne escritos acerca das relações entre linguagem, lógica e modos de saber; notas sobre os escritores Franz Kafka e Marcel Proust; registros bibliográficos e, ainda, uma anotação sobre a concepção de aura. A origem destes materiais remete às condições inadequadas de seu exílio na França.

Impossibilitado de permanecer em uma Alemanha Nazista, Benjamin viajou para Paris, cidade pela qual cultivava profunda admiração. O conteúdo notório destas reflexões contrasta com os suportes nos quais estão registradas: todas as anotações foram feitas em papéis reduzidos, muitos de menor qualidade, cujos espaços Benjamin aproveitou ao máximo, rascunhando-os compulsivamente em uma espécie de ânsia produtiva que o fez antecipar seu trágico final. Em uma reduzida folha de papel digitalizada (uma das únicas com tradução direta para o espanhol no livro) é possível se deparar com uma pequena reflexão cuja temática remete a uma das obras mais conhecidas de Benjamin e a última finalizada antes de sua morte, "Sobre o conceito de história”. A tradução em espanhol desta anotação consta no livro: "Marx dice que las revoluciones son las locomotoras de la historia universal. Pero quizá esto no sea así. Quizá sean las revoluciones el cable del freno de emergencia que el género humano que viaja en ese tren acciona”² (BENJAMIN apud MARX, 1944, p. 44).

Benjamin foi um crítico da noção de progresso. Para ele, a crença cega no desenvolvimento tecnológico e moral, fruto das revoluções liberais, impelia as sociedades ocidentais a um mito conformista, calcado na idealização de um porvir imaginado como necessariamente superior ao presente. Acreditava que esta ditadura da crença no progresso enlouquecia e envenenava a humanidade. Criava-se, assim, uma ilusão; uma miragem. A retórica da evolução civilizatória havia levado o mundo contemporâneo, na concepção de

\footnotetext{
2 “Marx diz que as revoluções são as locomotivas da história universal. Mas, talvez, isso não seja assim. Talvez sejam as revoluções o cabo de freio de emergência que o gênero humano que viaja nesse trem aciona.”
} 
Benjamin, ao abismo; à aceleração catastrófica do tempo. Benjamin denunciava o domínio irreversível do ser humano sobre a natureza; a perda das sensibilidades pelas experiências coletivas; o desdém pelas tradições.

Há, em seus arquivos, seis fotografias de brinquedos russos, conservadas após a sua morte (SCHWARZ, 2010, p. 72). Viajara para a União Soviética e, deparando-se com estas raridades em um museu, passou a colecioná-las. Estas miudezas, construídas em casas relegadas à extinção, tornavam possível a rememoração. Benjamin, como seus arquivos denotam, foi um homem de obsessões. Admirou a fragilidade das tradições, com sabor pela lentidão. Para muitos, fora um espírito do século XX com predileção pelo ritmo da era préindustrial. Pôde se contrapor às grandes catástrofes ao intensificar uma sensibilidade pelo diminuto, pelo evanescente; pelo periférico. Alocava-se, com isso, na melancolia do passado e nos detalhes.

Benjamin desenvolveu a competência de catalogar seus conhecimentos, cultivando a estratégia de dispersar seu material sob as mãos de pessoas e abrigos de lugares rigorosamente selecionados. A obsessão por brinquedos russos exprime, metaforicamente, este idealismo. Acreditava, contudo, na posteridade. Cultivou um misticismo judaico e o apelo pelo messianismo até seus últimos dias. Ainda que duvidasse do desenfreado progresso e dos cativeiros das liberdades, lutava pela sobrevivência de seus arquivos e, desta maneira, pelo próprio futuro, em um constante duelo contra a fogueira do tempo. Eis sua solução revolucionária: tornar-se um compulsivo colecionador. Eis a esperança de que, simbolicamente, pudesse sobrepor-se à curta experiência neste mundo. É sobre a permanência de um amplo legado, juntamente com os esforços de lançar novos questionamentos sobre a trajetória do emblemático intelectual do século XX, que este livro nos faz pensar. 